\title{
USE OF BEEF TALLOW AS AN ALTERNATIVE FOR CONSOLIDATION OF BIODIESEL PRODUCTION IN BRAZILIAN STATE OF TOCANTINS: A STUDY OF OXIDATIVE STABILITY VIA SPECTROSCOPY ANALYSIS IN THE UV-VIS.
}

\author{
PRADO, Carolina Porto ${ }^{1 *}$; DE FIGUEREDO, Kytéria Sabina Lopes²; RIBEIRO, Igor Hernandes \\ Santos ${ }^{3}$;
}

\author{
1,2,3 Universidade Federal do Tocantins, Campus Universitário de Gurupi, Departamento de Química Ambiental, \\ Rua Badejós, Chácaras n 69/72, Zona Rural, cep 77402970 - Gurupi, TO - Brasil \\ (fone: +5563 33113512; caixa postal 66) \\ * Autor correspondente \\ e-mail:carolinaprados@mail.uft.edu.br
}

Received 12 January 2015; received in revised form 23 January 2015; accepted 04 February 2015

\section{RESUMO}

O Brasil tem despontado como produtor de combustíveis alternativos derivados de biomassa, como o biodiesel, que pode substituir o diesel fóssil e é menos poluente. No entanto, existe uma concentração de renda na cadeia produtiva, pois a maior parte do biodiesel produzido no mundo é derivada do óleo de soja proveniente de grandes produtores. Esse cenário também corresponde ao Brasil, e ao estado do Tocantins que não conseguiu se enquadrar no Programa Nacional de Produção do Biodiesel. Neste estudo, o biodiesel foi produzido a partir de sebo bovino obtido de um frigorífico na cidade de Gurupi-TO. O sebo foi caracterizado no seu estado bruto, tratado e em seguida, o biodiesel foi sintetizado. Estudou-se a sua estabilidade à oxidação via análises espectroscópicas no UV-vis, e observou-se que o biodiesel de sebo apresentou aumento da absorção em $234 \mathrm{~nm}$ e redução em $268 \mathrm{~nm}$ após stress oxidativo. Verificou-se um estágio inicial de oxidação após o sétimo dia com a concentração máxima dos compostos primários de oxidação. Obteve-se, portanto um biodiesel satisfatório dentro de alguns dos parâmetros da Agência Nacional do Petróleo, Gás Natural e Biocombustíveis (ANP).

Palavras-chave: Biodiesel, Sebo bovino, Sustentabilidade, Estabilidade oxidativa, Esterificação.

\section{ABSTRACT}

Brazil has emerged as producer of alternative fuels derived from biomass, such as biodiesel, which can replace fossil diesel and is less polluting. However, there is a concentration of income in the production chain, since most of the biodiesel produced in the world is derived from soy oil from major producers. This scenario also corresponds to Brazil, and Tocantins state could not frame in the National Program for Biodiesel Production. In this study, the biodiesel was produced from beef tallow obtained from slaughterhouses in the city of Gurupi-TO. The beef tallow was characterized in its raw state, processed and then the biodiesel was synthesized. We studied the oxidation stability through spectroscopic analysis in the UV-vis, and we observed their stability to oxidation via spectroscopic analysis in the UV-vis, and observed that the beef tallow biodiesel showed increased absorption in $234 \mathrm{~nm}$ and $268 \mathrm{~nm}$ after reduction in oxidative stress. We checked an early stage of oxidation after the seventh day with the maximum concentration of primary oxidation compounds. We obtained a satisfactory biodiesel within some of the parameters of the National Agency of Petroleum, Gas Naturale Biofuels (ANP).

Keywords: Biodiesel, Beef tallow, Sustainability, Oxidative stability, Esterification. 


\section{INTRODUÇÃO}

O aumento da demanda e a pouca oferta de fontes energéticas, tem provocado conseguintes crises energéticas ao planeta. É fato que a matriz energética do planeta é sustentada pelos combustíveis fósseis. Mas além da preocupação com o meio ambiente $\mathrm{e}$ economia, a sociedade está em busca de novas fontes de energia que sejam renováveis, não poluam e que sejam viáveis financeiramente (KNOTHE, 2006).

O biodiesel apresenta-se como uma ótima alternativa de combustível por ser sintetizado a partir de matérias-primas renováveis (óleos vegetais, ou gorduras animais) e também tem menor emissão de gases poluentes (KNOTHE, 2006). A possibilidade de um combustível que substitua total ou parcialmente o diesel sem necessidade de qualquer adaptação nos motores à combustão interna e adicionalmente diminua a dependência pela produção externa de petróleo bem como a carga poluente para o meio ambiente levou o biodiesel a ocupar uma posição de destaque na economia. $O$ uso de óleos vegetais como combustível foi reconhecido desde o desenvolvimento dos primeiros motores a diesel, mas isso é limitado pela alta viscosidade, baixa volatilidade e caráter poli insaturado do óleo (BAO \& SHI, 2007; FERRARI et. al., 2005). Quimicamente o biodiesel trata-se de uma mistura de ésteres alquílicos de ácidos graxos obtidos principalmente a partir da conversão dos triacilglicerídeos constituintes de óleos e gorduras em ésteres (PRADOS, 2010).

O biodiesel proporciona ainda uma série de vantagens como combustível em relação a combustíveis derivados do petróleo, como: ser livre de enxofre e compostos aromáticos, alto número de cetano, médio teor de oxigênio, maior ponto de fulgor, menor emissão de partículas, menor toxicidade em comparação ao diesel de origem fóssil, além de ser biodegradável, entre outras vantagens (GERGIANNI et. al., 2008).

A transesterificação é a principal rota de produção de biodiesel no Brasil. Onde um mol de triacilglicerol reage com três mols de álcool (metanol ou etanol), com auxílio de um catalisador homogêneo, heterogêneo ou enzimático. $O$ processo mais comum é a transesterificação metílica do óleo vegetal em meio alcalino. Há uma dissolução de hidróxido de sódio ou de potássio no álcool utilizado como agente de transesterificação, essa reação gera alcoxido e água, e este hidrolisa os ésteres graxos, diminuindo assim o rendimento da alcoólise (RAMOS, 2011). Os íons alcóxidos, adicionados diretamente ao meio de reação ou produzidos, fazem um ataque nucleofílico no carbono da carbonila do triacilglicerol, levando a formação de um intermediário tetraédrico. Este intermediário elimina uma molécula de éster metílico e forma outro íon alcóxido que irá dar origem a um diacilglicerol. Com a repetição deste processo por mais dois ciclos tem-se a formação de mais duas moléculas de ésteres metílicos e uma molécula de glicerol (CORDEIRO, 2011). De acordo com a matéria prima utilizada, o biodiesel produzido terá diferentes características. A estrutura molecular do éster alquílico de ácido graxo formado pode variar de acordo com o tamanho da cadeia carbônica, número de instaurações, grupos ligados na cadeia, como as hidroxilas. Com isso foi necessário estabelecer alguns padrões de qualidade com o intuito de definir parâmetros que convenha sua utilização de tal forma que não seja prejudicado a qualidade das emissões de gases proveniente da combustão, o desempenho e a integridade do motor, além do transporte e manuseio do combustível (LÔBO, 2009). No entanto contaminantes podem surgir pelo processo de produção ou até mesmo pela estocagem do biodiesel como: fósforo, enxofre, cálcio e magnésio que são oriundos da matéria prima. Podem também ser encontrados na produção de biodiesel via transesterificação glicerol, sabões, resíduos de matéria prima, catalisador residual e álcool (LÔBO, 2009).

O Brasil conta com indústria de biodiesel consolidada, com mais de 50 usinas aptas a produzir e comercializar biodiesel, com uma capacidade instalada superior a 6 milhões de metros cúbicos(MME,2014). E com o intuito de alcançar uma matriz energética renovável e independência do diesel mineral, em 2004 o governo brasileiro criou o Programa Nacional de Produção e Uso do Biodiesel (PNPB) este programa surgiu com o intuito de viabilizar a produção e o uso de biodiesel no Brasil. Com ênfase na competitividade, na qualidade do biocombustível produzido, na garantia de segurança, na diversificação das matérias primas, no fortalecimento das potencialidades regionais para produção e na inclusão social dos agricultores familiares (MDA, 2010). Dessa forma 
a indústria que adquirisse matéria prima dos pequenos produtores ganhava o Selo do Combustível e com isso recebiam isenções fiscais (MME, 2004). No entanto, podem-se verificar algumas falhas no PNPB quanto ao aspecto social. Há a desvalorização dos pequenos pecuaristas como prováveis produtores de biodiesel, pois o biodiesel a partir de gordura animal não está contemplado para a aquisição do selo de combustível social. Além disso, a maioria das indústrias de biodiesel de sebo já é anexa aos grandes frigoríficos, dessa forma os pequenos pecuaristas não tem benefícios, pois só recebem pelo animal vendido, sem participação alguma na venda dos resíduos, inclusive o sebo (MARTINS et. al., 2011). Milazzo et. al., (2013), propõe que a sustentabilidade deveria ser adotada como instrumento de política social no PNPB, e não só como um programa de energia. Pois nem sempre alternativas economicamente viáveis contribuem para a implantação social, assim critérios de sustentabilidade para a produção de biodiesel devem ser avaliados. Dentre as matérias-primas que podem ser empregadas para a produção de biodiesel, a utilização de óleos vegetais propicia um biodiesel de ótima qualidade, mas há um valor agregado em determinados óleos, principalmente os destinados à indústria alimentícia, que torna inviável economicamente a produção do biodiesel (FIORESE, 2009).

Parente (2003) destaca que o biodiesel pode ser produzido a partir de qualquer óleo que se enquadre na categoria de óleos fixos ou triacilglicerídicos, portanto óleos de gorduras de animais são moléculas triacilglicerídicas compostas de ácidos graxos combinados com o glicerol, o que os tornam uma excelente alternativa de custo benefício para a produção de biodiesel.

A utilização de gordura animal na produção de biodiesel permite a expansão da produção do biocombustível sem a concorrência com matérias-primas de caráter alimentício, como a soja. O sebo é um resíduo gerado a partir do abate de animais, principalmente bovinos, o uso do sebo para a produção de biodiesel apresenta algumas vantagens como: não concorre com os alimentos, é biodegradável, e tem propriedades lubrificantes, por apresentar cadeias de ácidos graxos mais saturados em sua maioria e suporta melhor a oxidação (BOBBIO E $B O B B I O, 2003)$. Quanto à composição química a gordura animal difere dos óleos vegetais, nos tipos e distribuições de ácidos graxos nas moléculas de triacilglicerídeos, e por ser mais rico em ácidos graxos saturados (PRADOS, 2010). O seu alto teor de ácido esteárico (C18:0) e palmítico (C14:0) lhe confere propriedades como alta viscosidade, alto ponto de resfriamento de filtro a frio, entretanto o caráter saturado da gordura animal leva a uma melhor estabilidade oxidativa que é um parâmetro limitante do uso e armazenamento do biodiesel (TEIXEIRA, et. al., 2009).

A produção de biodiesel a partir de sebo bovino merece uma ênfase maior, pois evita o despejo inadequado dos resíduos animais. Esses resíduos quando não tratados corretamente podem chegar aos corpos hídricos causando poluição e outros problemas como a eutrofização. Deste modo, o uso do sebo para a produção de biodiesel propicia uma forma ambientalmente correta de descarte do resíduo animal (LEVY, 2011).

Entretanto a falta de qualidade do sebo entregue aos produtores de biodiesel afeta a competitividade do sebo bovino. A má qualidade pode estar associada ao processo de obtenção do sebo pelas graxarias bem como ao transporte da matéria-prima até as usinas. O sebo bovino é um produto altamente perecível e as longas distâncias entre graxarias e usinas podem prejudicar o processo de produção de biodiesel (LEVY, 2011).

O biodiesel produzido a partir do sebo bovino apresenta alguns problemas que podem afetar sua utilização nos motores. De acordo com Cardoso (2006), apresenta ponto de entupimento de filtro a frio (PEFF) de $19^{\circ} \mathrm{C}$, no limite máximo estabelecido pela (Resolução ANP $\mathrm{N}^{\circ} 7$, de 19/03/2008 - DOU 20/03/2008). Outra vertente a ser destacada é a alta viscosidade do biodiesel, causada pelo alto teor de ácidos graxos saturados presente no sebo, que dificulta a fluidez do combustível, e segundo Moraes (2008), pode gerar problemas no sistema de injeção dos motores. No entanto, um estudo realizado por Milli (2011), demonstrou que o sebo associado a óleos vegetais como o de algodão e óleo de canola, obteve resultados satisfatórios nas proporções 40:60 (sebo/óleo de algodão) e 60:40 (sebo/óleo de canola), o que tornou a produção viável economicamente, e de acordo com as características adquiridas foi possível 
evidenciar que o combustível produzido poderia ser substituído como alternativo ao óleo diesel.

O estado do Tocantins apresenta grande potencial para a produção de biodiesel, pois tem baixa densidade demográfica e grande quantidade de terra para plantio e juntamente com as boas condições de logísticas que estão sendo implantadas como: a Ferrovia Norte-Sul e a hidrovia Araguaia -Tocantins, além das 42 mil famílias de agricultores já contabilizados (RODRIGUES, 2011). Atualmente o Tocantins tem instalado apenas duas usinas de biodiesel localizadas na área central do estado, onde são utilizados como matéria prima somente oleaginosas como a soja e o pinhão-manso. No entanto o estado ocupa a decima posição em quantidade de rebanho bovino, possui seis frigoríficos em atividade e abate cerca de $25 \mathrm{mil}$ cabeças por mês (IBGE, 2013). Deste modo esse estudo teve como objetivos sintetizar biodiesel a partir do sebo bovino fornecido por frigoríficos como é fornecido para as indústrias de biodiesel, caracterizar e analisar a estabilidade à oxidação via análises espectroscópicas por UV-vis da matéria-prima bruta, tratada e o biodiesel produzido. Visando a consolidação da produção de biodiesel de sebo bovino no estado do Tocantins, como uma alternativa para inserir o estado no Programa Nacional de Produção e Uso de Biodiesel fazendo com que o estado passe a atender aos objetivos do PNPB principalmente em relação à sustentabilidade.

\section{PARTE EXPERIMENTAL:}

\subsection{Caracterização do Sebo}

O sebo bovino bruto foi caracterizado quanto ao índice de acidez e índice de saponificação a fim de se determinar os procedimentos de pré-tratamento necessários para obtenção de rendimento satisfatório na transesterificação bem como qualidade adequada do biodiesel.

\subsection{1 Índice de Acidez}

O índice de acidez foi determinado de acordo com método oficial AOCS (1997). Previamente, preparou-se solução de $\mathrm{NaOH} 0,1$ mol. $\mathrm{L}^{-1}$ devidamente padronizada. Pesou-se 14,2 $\mathrm{g}$ de sebo em erlenmeyer de $250 \mathrm{~mL}$ ao qual adicionou-se $50 \mathrm{~mL}$ de etanol anidro. Procedeuse à agitação mantendo a mistura homogênea a uma temperatura média de $70^{\circ} \mathrm{C}$. Adicionou-se 2 gotas de fenolftaleína $1 \%$ e titulou-se com a solução de $\mathrm{NaOH} 0,1$ mol.L-1 padronizada até coloração rósea. Anotou-se o volume $\left(\mathrm{V}_{\mathrm{NaOH}}\right)$ que foi aplicado juntamente com a massa do sebo $\left(m_{\text {sebo }}\right)$ e a concentração da solução de $\mathrm{NaOH}(\mathrm{N})$ na equação 1 para obtenção do índice de acidez (I.a).

$$
I a=\frac{V_{\mathrm{NaOH}} \times N \times 28,2}{m_{\text {sebo }}}
$$

O mesmo procedimento foi realizado para todas as amostras (sebo bruto, sebo degomado, sebo esterificado e biodiesel de sebo).

\subsection{2 Índice de Saponificação}

Preparou-se solução alcoólica de $\mathrm{KOH}$ 0,5 mol. $\mathrm{L}^{-1}$, dissolvendo-se $\mathrm{KOH}$ em $20 \mathrm{~mL}$ de água e completando o volume para $1 \mathrm{~L}$ com etanol anidro. Deixou-se a solução em repouso por $24 \mathrm{~h}$. Titulou-se alíquotas de $25 \mathrm{~mL}$ dessa solução com $\mathrm{HCl} \quad 0,5 \quad \mathrm{~mol} . \mathrm{L}^{-1}$ previamente padronizado, empregando-se fenolftaleína como indicador, obtendo-se o valor de "a" (equação 2). Pesou-se aproximadamente $2,0 \mathrm{~g}$ do sebo ( $\left.\mathrm{m}_{\text {sebo }}\right)$ e adicionou-se $25 \mathrm{~mL}$ da solução alcoólica de $\mathrm{KOH}$. Montou-se um condensador de refluxo e aqueceu-se o frasco em banho-maria por 1 hora com agitação ocasional. Titulou-se, então, o excesso de $\mathrm{KOH}$ na solução ainda quente com $\mathrm{HCl} 0,5 \mathrm{~mol} . \mathrm{L}^{-1}$ e fenolftaleína como indicador obtendo-se o valor de "b" (equação 2).

$$
I s=\frac{(a-b) \times 0,5 \times 56,1}{m_{\text {sebo }}}
$$

O mesmo procedimento foi realizado para todas as amostras (sebo bruto, sebo degomado, sebo esterificado e biodiesel de sebo).

\subsection{Pré-tratamento}

\subsubsection{Extração de compostos polares}

Em um erlenmeyer foram adicionados volumes iguais de água destilada e sebo e submetido a aquecimento a $70{ }^{\circ} \mathrm{C}$ com agitação magnética por $1 \mathrm{~h}$. As fases orgânicas e aquosas foram separadas por decantação em funil de separação.

\subsubsection{Esterificação ácida}

Foram dissolvidos $0,3 \mathrm{~mL}$ de $\mathrm{H}_{2} \mathrm{SO}_{4}$ concentrado em $28 \mathrm{~mL}$ de metanol, posteriormente adicionados a $140 \mathrm{~g}$ de sebo 
aquecido. Manteve-se a mistura em refluxo por $3 \mathrm{v}$. horas à temperatura de $65^{\circ} \mathrm{C}$, em capela. $\mathrm{O}$ metanol foi retirado em evaporador rotativo, e após decantação da mistura por 4 horas retirouse a fase aquosa e lavou-se a fase oleosa com água morna 5 vezes.

\subsection{Transesterificação básica}

Pesaram-se $80 \mathrm{~g}$ do sebo $(\mathrm{MM}=796,54$ g. $\left.\mathrm{mol}^{-1}\right)$ em erlenmeyer de $250 \mathrm{~mL}$ ao qual se adicionou o $\mathrm{KOH}\left(2 \% \mathrm{~m}_{\mathrm{KoH}} / \mathrm{m}_{\text {sebo }}\right)$ solubilizado em metanol (razão molar de 9:1 metanol/sebo). A reação foi mantida sob agitação magnética por 2 h a $65^{\circ} \mathrm{C}$ (Prados, 2011). Separou-se o biodiesel e o glicerol após 24 horas de repouso em funil de separação e lavou-se o biodiesel com água morna por 3 vezes e solução de ácido cítrico quente $5 \%$ até neutralização da água de lavagem. $\mathrm{O}$ produto foi colocado na estufa por 2 horas a $80^{\circ} \mathrm{C}$ e submetido à filtração com sulfato de sódio anidro para retirada de resíduos de água.

\subsection{Espectroscopia UV-vis}

Os espectros de absorção do biodiesel foram obtidos em espectrofotômetro UV/Vis (T70 UV-vis Spectrometer PG Intruments LTDA) com varredura de 200 a 400nm. E a absorbância para ésteres, ácidos carboxílicos, compostos primários de oxidação e compostos secundários de oxidação foram obtidas nos comprimentos de onda específicos: 205, 232 e 268 respectivamente. A análise espectroscópica na região do UV-vis foi empregada para diferenciar as amostras de sebo e de biodiesel qualitativamente ao longo das etapas de tratamento, síntese e armazenamento. Para isso foram analisadas alíquotas das seguintes amostras com diluição 1:1000 em diclorometano (Almeida, 2007):

i. Sebo bruto: amostra de sebo obtida diretamente do frigorífico (Matadouro Municipal de Gurupi/TO);

ii. Sebo degomado: amostra de sebo submetida a um processo de purificação por extração de compostos polares;

iii. Sebo esterificado: amostra de sebo que passou por reação e esterificação ácida para converter os ácidos graxos livres em ésteres;

iv. Biodiesel de sebo: amostra de biodiesel de sebo obtida por transesterificação básica e armazenada ao abrigo de luz e calor;
Biodiesel de sebo oxidado: amostra de biodiesel de sebo exposta a condições oxidantes (oxidado por duas horas em estufa a $120{ }^{\circ} \mathrm{C}$ e armazenado em presença de luz e calor por 7, 14 e 21 dias).

As soluções foram preparadas em balões de $100 \mathrm{~mL}$

\section{RESULTADOS E DISCUSSÃO:}

Os valores encontrados para os índices de acidez (IA) e de saponificação (IS) das amostras de sebo bruto e tratado por extração de compostos polares e esterificação ácida estão expostos na Tabela 1. Como ambas as propriedades revelam o estado de conservação da matéria prima forma empregados como forma de monitorar a qualidade do sebo nas etapas de pré-tratamento.

Tabela 1: Índices de acidez (IA) e saponificação (IS) para o sebo bruto, o tratado por remoção de compostos polares e o tratado por esterificação ácida.

\begin{tabular}{c|c|l}
\hline Amostra & $\begin{array}{c}\text { IA } \\
\text { (mg KOH/g) }\end{array}$ & $\begin{array}{c}\text { IS } \\
\text { (mg KOH/mg) }\end{array}$ \\
\hline Sebo bruto & 10,500 & 0,126 \\
$\begin{array}{c}\text { Sebo da } \\
\text { extração } \\
\begin{array}{c}\text { Sebo } \\
\text { esterificado }\end{array}\end{array}$ & 9,780 & 0,126 \\
\hline
\end{tabular}

O índice de acidez do sebo bruto de 10 , $500 \mathrm{mg} \mathrm{KOH} / \mathrm{g}$ de sebo está muito acima dos encontrados na literatura entre 0,4 e $0,5 \mathrm{mg}$ de $\mathrm{KOH} / \mathrm{g}$ de gordura (MORAES, 2008; MA et. al., 1998). Esse valor indica que o processo de extração da gordura foi realizado em condições que levaram à degradação do sebo, além disso, outras formas de refino como a utilização de adsorventes poderiam ser testados. Os triacilglicerídeos, constituintes do mesmo, em presença de: umidade, oxigênio e elevação de temperatura se alteram quimicamente através de hidrólise, oxidação e alteração térmica (JORGE, 2005). Dentre os produtos destes processos estão os ácidos graxos responsáveis pela elevada acidez que compromete o rendimento da 
reação. Isso porque os ácidos graxos livres presentes na matéria-prima podem diminuir o rendimento em ésteres da reação de transesterificação levando à reação de saponificação. O sabão formado consome o catalisador diminuindo sua eficiência. Além disso, causa aumento da viscosidade, formação de gel e dificuldade de separação entre o biodiesel e o glicerol (FUKUDA, 2001).

O índice de saponificação, por outro lado, pode revelar a pureza da matéria-prima, quanto menor o índice de saponificação maior a quantidade da matéria insaponificável que prejudica o desempenho do combustível bem como o rendimento da síntese. O sebo bruto apresentou valor de índice de saponificação de $0,126 \mathrm{mg} \mathrm{KOH} / \mathrm{mg}$ de sebo abaixo dos valores encontrados por volta de $0,186 \mathrm{mg} \mathrm{KOH} / \mathrm{mg}$ de sebo (CHIU e GIOIELLI, 2002). O baixo índice de saponificação do sebo é devido à presença de substâncias polares de origem biológica inerente a este tipo de material como esteróis, produtos de degradação, hidrocarbonetos de cadeia curta e outros, que devem ser eliminados por levar a um baixo rendimento de reação além provocar formação de borra insolúvel no produto final (PAULA et. al., 2011).

Para evitar os problemas decorrentes da elevada acidez e baixo índice de saponificação da matéria-prima o sebo passou por extração de compostos polares e esterificação ácida. É possível observar que o processo de extração aquosa pouco alterou os parâmetros analisados, diminuindo o índice de acidez sensivelmente para $9,78 \mathrm{mg}$ de $\mathrm{KOH} / \mathrm{g}$ de sebo, através da extração de compostos ácidos de cadeia curta.

Alguns autores, no entanto, destacam que somente com a água é possível a remoção de boa parte da matéria insaponificável que é polar, sem submeter à matéria-prima a processos mais agressivos (MORAIS, 2012). Nota-se, entretanto, que a esterificação dos ácidos graxos livres através da catálise ácida se mostrou eficiente reduzindo o índice de acidez para $2,27 \mathrm{mg}$ $\mathrm{KOH} / \mathrm{g}$ de sebo, valor mais próximo de outros autores que com o mesmo processo alcançaram índices de acidez menores que $2 \mathrm{mg}$ de $\mathrm{KOH} / \mathrm{g}$ de gordura (LIU, 1994, MITTELBACH et. al, 1992). Banković-llić et. al., (2014), destaca que este tipo de pré-tratamento é promissor no aumento da velocidade da reação, rendimento em ésteres e formação de sabões na obtenção do biodiesel. Observou-se um pequeno aumento no índice de saponificação devido à eliminação de algumas impurezas polares no processo de esterificação ácida.

Após a obtenção de um biodiesel com baixo índice de acidez procedeu-se a transesterificação básica. Foi observada perfeita separação de fases (Figura 1), sem a presença de emulsões que evidenciam baixo rendimento em ésteres.

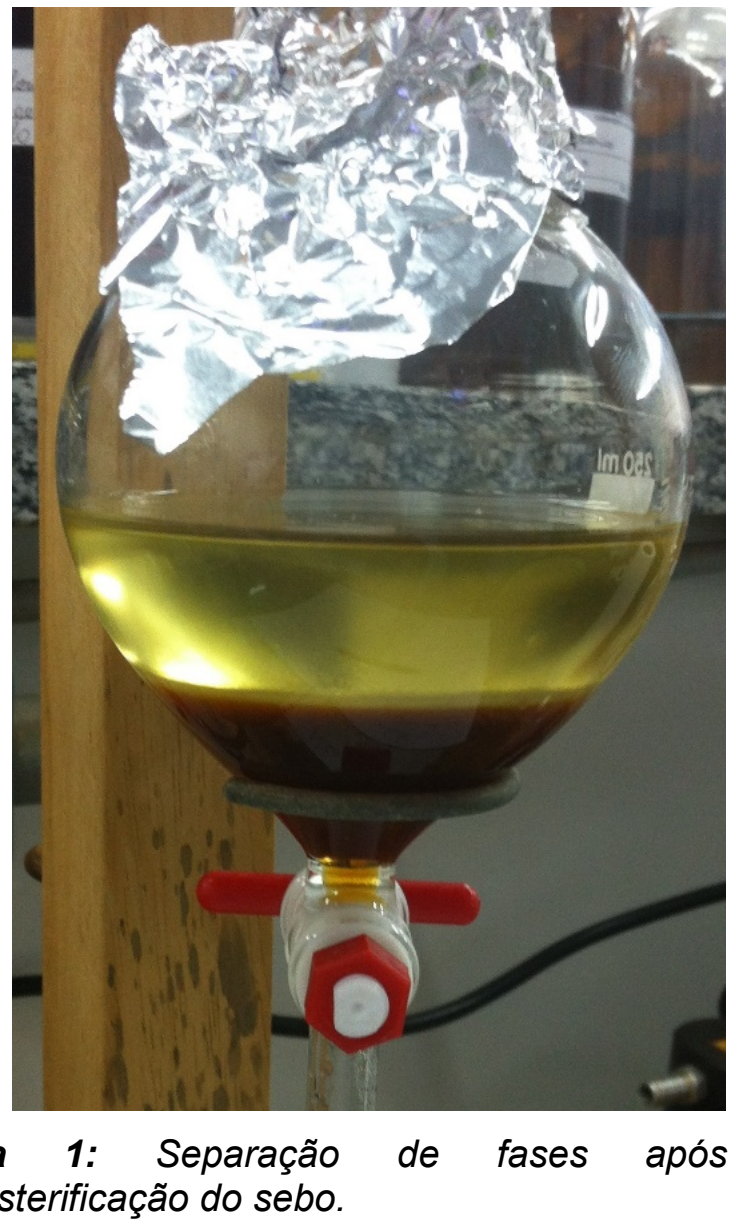

A reação apresentou rendimento em massa de $62 \%$ de ésteres metílicos, a perda de massa da fase de biodiesel ocorreu devido às sucessivas filtragens visando um biodiesel puro. O índice saponificação foi empregado para verificar a formação dos ésteres no biodiesel (VASCONCELOS e GODINHO, 2002). Após a transesterificação o índice de saponificação foi elevado para 0,197 $\mathrm{mg}$ de $\mathrm{KOH} / \mathrm{g}$ de biodiesel o que é muito próximo dos valores encontrados na literatura (MORAES, 2008). É importante ressaltar que os materiais insaponificáveis apresentam ponto de ebulição mais elevado o que provoca acúmulo de resíduos no motor e a carreta em processos de abrasão (PAULA et. al., 
2011).

O índice de acidez encontrado para o biodiesel foi $0,513 \mathrm{mg}$ de $\mathrm{KOH} / \mathrm{g}$ de sebo, no limite estabelecido pela ANP que é de $0,5 \mathrm{mg}$ do $\mathrm{KOH} / \mathrm{g}$ de sebo. Um alto índice de acidez pode significar a presença de água no produto, isso pode deslocar o equilíbrio de algumas reações e formar alguns compostos indesejáveis, e assim danificar o motor (KNOTHE, 2006). Além disso, os ácidos graxos livres no biodiesel têm efeito catalítico de pró-oxidação, acelerando a degradação do combustível (MIYASHITA e TAKAGI, 1986).

O biodiesel obtido foi submetido a ensaios oxidação que foram acompanhados por UV-vis. A espectroscopia na região do UV e visível é capaz de fornecer importantes informações qualitativas de compostos orgânicos. No comprimento de onda de $205 \mathrm{~nm}$, por exemplo, tem-se a absorção característica de ácidos carboxílicos e ésteres (SKOOG, 2002), e pôde ser utilizada para verificar alterações nos teores de ácidos graxos e ésteres no biodiesel. A análise das absorbâncias das amostras de sebo bruto, sebo degomado, sebo esterificado, biodiesel de sebo e biodiesel de sebo esterificado neste comprimento de onda forneceu os valores apresentados na Tabela 2.

Tabela 2 - Absorbâncias do sebo bovino antes e depois dos tratamentos em $205 \mathrm{~nm}$.

\begin{tabular}{l|l}
\hline Amostra & $\begin{array}{l}\text { Absorbância } \\
\text { em 205 nm }\end{array}$ \\
\hline Sebo bruto & 0,208 \\
Sebo da extração & 0,224 \\
Sebo esterificado & 0,226 \\
Biodiesel de sebo & 0,150 \\
Biodiesel de sebo oxidado* & 0,101 \\
Biodiesel de sebo oxidado & 0,072 \\
$\mathbf{7}$ dias & \\
\hline
\end{tabular}

${ }^{*}$ Duas horas em estufa a $120^{\circ} \mathrm{C}$.

De acordo com os dados expostos na tabela 2 é possível observar o aumento do valor da absorbância na região de $205 \mathrm{~nm}$ entre a amostra de sebo bruto e de biodiesel. Este incremento corresponde à soma das absorbâncias dos triacilglicerideos e ácidos graxos livres. A extração de compostos polares não demonstrou muita eficiência na diminuição do índice de acidez, mas houve uma purificação, observou-se um leve aumento na absorbância nesse comprimento de onda para o sebo degomado em relação ao bruto. Já a absorbância do sebo esterificado não apresentou valor muito diferente do degomado porque os ácidos graxos livres presentes neste foram convertidos a ésteres no processo de esterificação e ambos os grupos funcionais absorvem nesta região. Por fim a absorbância do biodiesel foi menor, pois conforme verificado no índice de acidez do biodiesel, há uma diminuição significativa dos ácidos graxos livres na amostra e a absorbância é relativa aos ésteres que compõem o biodiesel. Para a amostra de biodiesel submetida a condições oxidantes (biodiesel de sebo oxidado) a absorção diminuiu porque parte dos ésteres que constitui o biodiesel foi degradada.

Já as medidas de absorção a 234 e 268 nm demonstram o grau de oxidação de óleos, gorduras e do próprio biodiesel, pois revelam a presença dos compostos primários e secundários oriundos da oxidação dos ácidos graxos (ALMEIDA, 2007 e FERRARI, 2009). A absorção nessa região refere-se à formação de dienos e trienos que é proporcional ao ganho de oxigênio e formação de peróxidos pelo processo de oxidação (ROVELLINE et al., 1997). Os ácidos graxos poliinsaturados que compõem o biodiesel e o sebo se oxidam formando hidroperóxidos e deslocando as duplas ligações, acarretando assim a formação de dienos conjugados que absorvem em $234 \mathrm{~nm}$. Já os produtos secundários da degradação oxidativa resultantes da etapa de término da reação em cadeia apresentam absorção máxima em $268 \mathrm{~nm}$.

Dessa forma é possível diferenciar os estados de oxidação através da relação entre a absorbância em 234 e 268 nm, se a absorbância é mais elevada em $234 \mathrm{~nm}$ o teor de peróxidos é elevado e esta situação define o estágio inicial da oxidação. Enquanto a absorbância mais elevada em $270 \mathrm{~nm}$ corresponde à maior quantidade dos compostos secundários caracterizando um estágio final da oxidação (FERRARI, 2009). O gráfico apresentado na figura 2 mostra as alterações nesses comprimentos de onda ao longo do processo de tratamento e oxidação do biodiesel. 


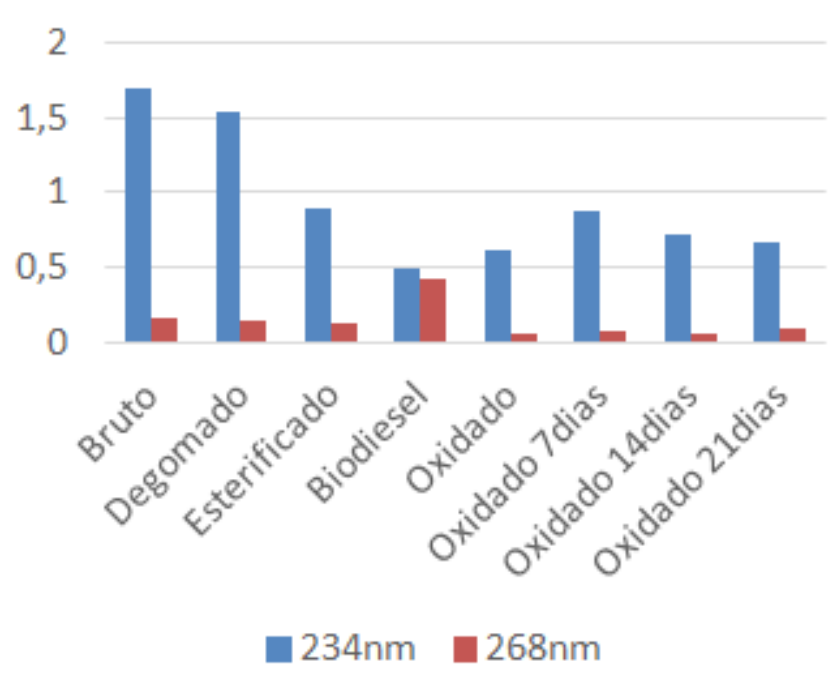

Figura 2: Gráfico de abosrbâncias do sebo bruto e tratado e do biodiesel durante stress oxidativo.

Nota-se que as absorbâncias em $234 \mathrm{~nm}$ diminuem à medida em que se submete o sebo aos tratamentos de extração de compostos polares e esterificação. Mostrando a eficiência do mesmo em diminuir os compostos de oxidação primária presentes no sebo bruto. Ressalta-se que a matéria prima encontra-se em estágio inicial de oxidação. Além disso, as absorbâncias para o sebo após a extração não são muito diferentes do sebo bruto evidenciando a ineficiência da extração de compostos polares, os dados corroboram com os valores de índice de acidez. A esterificação, por outro lado mostrou-se eficiente na eliminação principalmente dos compostos primários de oxidação. A diminuição significativa da absorbância em $234 \mathrm{~nm}$ do biodiesel em relação ao sebo demonstram a total eliminação dos compostos primários de oxidação e a qualidade do biodiesel obtido em termos de pureza.

O biodiesel submetido a stress oxidativo apresentou aumento da absorção em $234 \mathrm{~nm}$ e redução em $268 \mathrm{~nm}$, verificou-se, portanto, que esta amostra encontra-se em estágio inicial de oxidação e após 7dias tem-se a concentração máxima dos compostos primários de oxidação. Nota-se, entretanto, que este perfil se altera a partir daí e após 14 dias de oxidação têm-se uma diminuição dos compostos primários de oxidação e aumento nos compostos secundários de oxidação, essa tendência ocorre ainda até 21 dias de oxidação.

\section{CONCLUSÕES:}

O sebo bovino destaca-se como uma matéria prima promissora para a produção de biodiesel no estado do Tocantins, sendo este grande produtor agropecuário. Além disso, pode contribuir para a sustentabilidade e desenvolvimento ao agregar valor a um resíduo e promover inclusão econômica de pequenos pecuaristas. O presente trabalho demonstrou sua aplicabilidade na produção do biodiesel.

Observou-se que o sebo bovino extraído no frigorífico apresenta-se oxidado, mas que a extração de compostos polares e, principalmente, a esterificação ácida são eficientes tratamentos para a obtenção de uma matéria-prima de qualidade adequada.

A espectroscopia na região do UV mostrou-se adequada para acompanhamento dos tratamentos empregados na matéria prima. Foi possível verificar variações de absorbância nas regiões características dos ácidos graxos e das impurezas da matéria prima, demonstrando a eficiência dos processos de tratamento. Notouse ainda a eficiência do UV-vis para acompanhar o processo de degradação oxidativa do biodiesel produzido. A caracterização por UV permitiu confirmar a presença de compostos secundários no sebo, e a formação de compostos oxidados no biodiesel submetido a stress. Através desta técnica, concluiu-se que o biodiesel produzido mantém suas características por até sete dias quando armazenado em condições inadequadas.

\section{AGRADECIMENTOS:}

A Universidade Federal do Tocantins, pelo apoio ao estudo realizado.

\section{REFERÊNCIAS:}

1. ALMEIDA, A. A. F. Avaliação da oxidação do biodiesel etílico de milho por meio de técnicos espectroscópicos. 2007. Dissertação (Mestrado em Química) universidade Federal da Paraíba, João Pessoal - PB, 2007.

2. AOCS - American Oil Chemists' Society. Official methods and recommended practices. 5 ed. Champaign: AOCS, 1997. 
3. ANP - Agência Nacional de Petróleo, Gás Natural e Biocombustíveis. Resolução $\mathrm{n}^{\circ}$ 25 de 2 de fevereiro de 2008.Disponível em: www.anp.gov.br, acessado em 15 de Julho de 2014.

4. ANP - Agência Nacional de Petróleo, Gás Natural e Biocombustíveis. Resolução $\mathrm{n}^{\circ}$ 7 De 19 de Março de 2008. Disponível em: www.anp.gov.br, acessado em 15 de Julho de 2014.

5. BAO, Z.; SHI, H. Bioresource Technology. v. 99, p. 9025-9028, 2007.

6. BANKOVIĆ-ILIĆ, I. B., STOJKOVIĆ, I. J., STAMENKOVIĆ, O. S., VELJKOVIC, V. B. Hung, Y-T. Renew. Sust. Energ. Rev.32, 238, 2014.

7. BOBBIO, P.A. BOBBIO, F.O. Química do Processamento de Alimento. $3^{a}$ Ed. São Paulo, Varela. 2003.

8. CARDOSO, J.J.F.; COSTA, A.A.; ALMEIDA, M.A.P.M. CAIO, K.;CARDIAS,H.T. Anais do I congresso da Rede Brasileira de Tecnologia do Biodiesel, Brasília, 2006

9. CORDEIRO, C. S; SILVA, F. R; WYPYCH, Química Nova. vol.34 no.3 São Paulo. 2011.

10. CHIU, M. C., GIOIELLI, L. A. Ciênc. Tecnol. Aliment., 22, 151,2002.

11. FERRARI, R. A., OLIVEIRA, V. S., SCABIO, A. Quím. Nova, v. 28, n. 1, p. 19-23, 2005.

12. FIORESE, D. A. GOMES, L. F. S. Cultivando o Saber, Cascabel. v.2, 2009.

13. FUKUDA, H. AKIHIKO, K.; NODA, H. J. Biosc. Bioengineering. 92, 405, 2001.

14. GERGIANNI, K.G.; KONTOMINAS, M.G.; TEGOU, E.; AVLONITIS, D.; GERGIS, V.;. Energy Fuels, n. 5 , v. 21 , p. 30233027, 2008.

15. IBGE - Instituto Brasileiro de Geografia e Estatística. Censo Agropecuário de 2013. Disponível em: www.ibge.gov.br, acessado em 15 de Julho de 2014.

16. JORGE, N., SOARES, B. B. P., LUNARDI, V. M., MALACRIDA C. R. Quim. Nova, 28, 947,2005.
17. KNOTHE, G.; STEIDLEY, K. R. Energy Fuels, v 19. P. 1192-1200, 2005.

18. KNOTHE, G.; GERPEN, J.V.; KRAHL, J.; RAMOS, L.P.1 ${ }^{a}$ edição, São Paulo: Edgard Blucher, páginas 133 à 145, 2006.

19. LEVY, G. A inserção de sebo bovino na indústria brasileira do biodiesel: analise sob a ótica da Economia dos Custos de Transação e da Teoria dos Cistos de Mensuração. Dissertação Mestrado Escola superior de Agricultura Luiz Queiroz. USP, Piracicaba. 2011.

20. LIU K. J. Am. Oil. Chem. Soc.71, $1179,1994$.

21. LÔBO, I. P.; FERREIRA, L. C.. Quím. Nova, Vol. 32, No. 6, 1596-1608. 2009.

22. MA, F.; CLEMENTS, L. D.; HANNA, M. A. Ind. Eng. Chem. Res.,37, 3768,1998.

23. MARTINS, R.; NACHILUK, K.; BUENO,C.R.F.; FREITAS, S. de $M$. Informações Econômicas, São Paulo, v. 41, n. 5, maio 2011.

24. MDA - Ministério do Desenvolvimento Agrário. Disponível em: <http://portal.mda.gov.br/portal/saf/progra mas/biodiesel/2286313 >. Acesso em: Agosto. 2014.

25. MILAZZO, M. F.; SPINA, F.; PRIMERANO, P.; \& BART, J. C. J. Renew. And Sust. Energy Reviews, v. 26. 2013.

26. MILLI, B. B.; GRIPA, D. C.; SIMONELLI, G.; MARTINS, M. O. D. Enciclopédia Biosfera, Centro Científico Conhecer Goiânia, v. 7, n. 12, p.1-26, 2011.

27. MITTELBACH, M.; POKITS, B.; SILBERHOLZ, A. Proc. Of. An. Alter. Energy conference. Nashville USA, 1992.

28. MIYASHITA, K, TAKAGI, T. J. Am. Oil Chem. Soc. 63, 1380, 1986.

29. MME (Ministério das Minas e Energia). Governo Federal Autoriza Uso Comercial do Biodiesel. Disponível em: < http://www.abic.com.br/ >. Dezembro de 2004. Acesso em julho, 2014.

30. MORAES, M. F. A. Biodiesel de Sebo: Avaliação de propriedades e testes de 
consumo em motor a diesel. 2008. $118 f$. Dissertação (Mestrado em Química) Instituto de Química, Universidade Federal do Rio Grande do Sul, Porto Alegre, 2008. Disponível em: http://hdl.handle.net/10183/14351. Acesso em: 25 de Agosto de 2014.

31. MORAIS, M. M. Anais do VII Congresso Norte-Nordeste de Pesquisa e Inovação, Palmas, Brasil, 2012.

32. PARENTE, E. J. S., Biodiesel: uma aventura tecnológica num país engraçado. Unigráfica, Fortaleza, 2003.

33. PAULA, A., J, A. de, KRÜGEL, M., MIRANDA, J. P., ROSSI, L. F. S., NETO, P. R. C.. Quím. Nova. 34, 91,2011.

34. PRADOS, C. P. Determinação cromatográfica simultânea dos teores de ésteres totais, mono-, di- e triacilglicerídeos, glicerol livre e total em biodieseis metílicos ou etílicos. Dissertação Mestrado. Instituto de Química da Universidade Federal de Goiás. 2010.

35. PRADOS, C. P.; RESENDE, D. R.; BATISTA, L. R.; ALVES, M. I. R; ANTÔNIOSI FILHO, N. R. Fuel, v. 96, 476.2012
36. RAMOS, L. P.; SILVA, F. R.; MANGRICH, A. S.; CORDEIRO, C. Revista Virtual Química, Vol 3,No. 5. 2011

37. RODRIGUES, R.A. Biodiesel no Brasil: diversificação energética e inclusão social com sustentabilidade. In: Ferreira, J. R. \& Cristo, C. M. P. N. (coord.). O futuro da indústria: biodiesel (coletânea de artigos). Brasília: MDIC - STI/IEL 2011.

38. ROVELLINE, P.; CORTESI, N.; FEDELI, E. La Rivista Italiana delle Sostanze Grasse, v. 74, n. 5, p. 181 - 1891997.

39. SKOOG, D. A.; HOLLER, F.; NIEMAN, T. A. $5^{\circ}$ ed., Ed. Bookman, Porto Alegre, 2002.

40. TEIXEIRA, S.L.G.; ASSIS, J.C.; MENDONÇA, D.R.; SANTOS, I.T.V.; GUIMARÃES, P.R.B.; PONTES, L.A.M.; TEIXEIRA, S.R.J. Fuel Processing Technology, v. 90, p. 1164-1666, Salvador, 2009.

41. VASCONCELOS, AFF.; GODINHO, OES.. Quim Nova v.25: 1057-1060. 2002. 